\title{
Clinicopathological and prognostic significance of interleukin-8 expression and its relationship to KRAS mutation in lung adenocarcinoma
}

\author{
N Sunaga ${ }^{*}, 1,2$, K Kaira ${ }^{1,3}$, Y Tomizawa ${ }^{4}$, K Shimizu ${ }^{5}$, H Imai ${ }^{1}$, G Takahashi ${ }^{4}$, S Kakegawa ${ }^{6}$, Y Ohtaki ${ }^{5}$, \\ T Nagashima ${ }^{5}$, N Kasahara ${ }^{1}$, O Kawashima ${ }^{6}$, T Hisada $^{1}$, R Saito ${ }^{4}$ and M Yamada ${ }^{1}$ \\ ${ }^{1}$ Department of Medicine and Molecular Science, Gunma University Graduate School of Medicine, 3-39-15 Showa-machi, \\ Maebashi, Gunma371-8511, Japan; 2Oncology Center, Gunma University Hospital, 3-39-15 Showa-machi, Maebashi, \\ Gunma 371-8511, Japan; ${ }^{3}$ Department of Oncology Clinical Development, Gunma University Graduate School of Medicine, \\ 3-39-15 Showa-machi, Maebashi, Gunma 371-8511, Japan; ${ }^{4}$ Department of Respiratory Medicine, National Hospital Organization \\ Nishigunma Hospital, 2854 Kanai, Shibukawa, Gunma 377-8511, Japan; ${ }^{5}$ Department of Thoracic and Visceral Organ Surgery, \\ Gunma University Graduate School of Medicine, 3-39-15 Showa-machi, Maebashi, Gunma 371-8511, Japan and ${ }^{6}$ Department of \\ Thoracic Surgery, National Hospital Organization Nishigunma Hospital, 2854 Kanai, Shibukawa, Gunma 377-8511, Japan
}

Background: On the basis of our recent findings of oncogenic KRAS-induced interleukin-8 (IL-8) overexpression in non-small cell lung cancer, we assessed the clinicopathological and prognostic significances of IL-8 expression and its relationship to KRAS mutations in lung adenocarcinomas.

Methods: IL-8 expression was examined by quantitative RT-PCR using 136 of surgical specimens from lung adenocarcinoma patients. The association between IL-8 expression, clinicopathological features, KRAS or EGFR mutation status and survival was analysed.

Results: IL-8 was highly expressed in tumours from elderly patients or smokers and in tumours with pleural involvement or vascular invasion. In a non-smokers' subgroup, IL-8 level positively correlated with age. IL-8 was highly expressed in tumours with KRAS mutations compared with those with EGFR mutations or wild-type EGFR/KRAS. Lung adenocarcinoma patients with high IL-8 showed significantly shorter disease-free survival (DFS) and overall survival (OS) than those with low IL8. DFS and OS were significantly shorter in the patients with mutant KRAS/high IL-8 than in those with wild-type KRAS/low IL-8. Cox regression analyses demonstrated that elevated IL-8 expression correlated with unfavourable prognosis.

Conclusions: Our findings suggest that IL-8 expression is associated with certain clinicopathological features including age and is a potent prognostic marker in lung adenocarcinoma, especially in oncogenic KRAS-driven adenocarcinoma.

Lung cancer is the major cause of cancer-related death worldwide (Jemal et al, 2011). It is histologically divided into small cell lung cancer (SCLC) and non-small cell lung cancer (NSCLC). NSCLC represents $\sim 85 \%$ of all lung cancers and adenocarcinoma is the most common subtype of NSCLC (Travis et al, 2011). Recent advances in molecular biology have identified several driver mutations, such as EGFR mutations, EML4-ALK fusions and ROS1 fusions, which are used or being tested as biomarkers for

*Correspondence: Dr N Sunaga; E-mail: nsunaga@gunma-u.ac.jp

Revised 6 January 2014; accepted 4 February 2014; published online 27 February 2014

(c) 2014 Cancer Research UK. All rights reserved 0007-0920/14 
personalised therapy for lung adenocarcinoma (Chin et al, 2012; Pao and Hutchinson, 2012). KRAS mutations are the most common driver mutations in lung adenocarcinoma ( $\mathrm{Pao}$ and Hutchinson, 2012). KRAS encodes a small GTP-binding protein that has an essential role in the regulation of many cellular processes, including proliferation, differentiation and apoptosis (Suda et al, 2010). Despite the high incidence of KRAS mutation and its correlation with unfavourable prognosis in lung adenocarcinoma (Mascaux et al, 2005), no effective therapeutic strategies have been established to target this subtype of tumour. Therefore, further study is warranted to develop new therapeutic modalities to improve the prognosis for patients with oncogenic KRAS-driven lung adenocarcinoma.

The CXC chemokine interleukin-8 (IL-8), which was originally identified as a chemoattractant for neutrophils, has been shown to be a transcriptional target of RAS signalling in human cancer cells (Sparmann and Bar-Sagi, 2004). Subsequently, we reported that IL-8 expression is transcriptionally upregulated by oncogenic KRAS mutations in NSCLC (Sunaga et al, 2012). IL-8 is an essential proinflammatory mediator that is involved in cancer development and acts as an angiogenic growth factor that promotes cell proliferation and angiogenesis, thus contributing to the progression and metastasis of NSCLC (Smith et al, 1994; Arenberg et al, 1996; Wang et al, 1996; Yatsunami et al, 1997; Zhu et al, 2004; Boldrini et al, 2005; Luppi et al, 2007). IL-8 has also been implicated in the epithelial-mesenchymal transition and cancer cell stemness during tumour progression (Palena et al, 2012). Importantly, IL-8 overexpression has been associated with unfavourable prognosis in NSCLC (Bellocq et al, 1998; Yuan et al, 2000; Chen et al, 2003; Seike et al, 2007). However, the clinicopathological and prognostic roles of IL-8 and its relationship to KRAS mutation status in lung adenocarcinoma are still unclear. To address these issues, we conducted the present study using tumour specimens from lung adenocarcinoma patients.

\section{MATERIALS AND METHODS}

Tumour specimens from lung adenocarcinoma patients. Tumour specimens were obtained from 136 patients with primary lung adenocarcinoma who underwent surgery consecutively between July 2003 and September 2009 at the Gunma University School of Medicine Hospital and National Nishigunma Hospital in Gunma, Japan (Supplementary Table 1). At the data cut-off point (end December 2013), 29 patients had developed recurrence and 20 had died due to lung adenocarcinoma. Thirty patients received adjuvant chemotherapy with UFT $(N=12)$ or adjuvant platinumbased chemotherapy $(N=18)$. Among the patients with recurrent disease, 25 patients received EGFR-tyrosine kinase inhibitor (EGFR-TKI) therapy $(N=17)$ or platinum-based chemotherapy
$(N=8)$. All tumours were histologically diagnosed as adenocarcinomas according to the criteria of the World Health Organization. Postsurgical pathological stages were assigned according to the tumour-node-metastasis classification. Non-cancerous lung specimens $(N=10)$ that were obtained from 10 patients were used as normal controls. KRAS mutation at codon 12 and EGFR mutations in exons 19 and 21 were analysed using the Smart Amplification Process version 2 assay (DNAFORM, Kanagawa, Japan) followed by direct sequencing to confirm the presence of these mutations as previously described (Mitani et al, 2007; Miyamae et al, 2010; Sunaga et al, 2013). Disease-free survival (DFS) was defined as the time between surgery and the first evidence of recurrent disease, and overall survival (OS) was defined as the time between surgery and death. For the survival analysis, 17 patients who had received EGFRTKI therapy were excluded to avoid selection bias. The study protocol was approved by the institutional review board of Gunma University Graduate School of Medicine and National Nishigunma Hospital. The specimens were immediately frozen after collection and stored at $-80^{\circ} \mathrm{C}$ until mRNA extraction was performed.

Quantitative real-time RT-PCR. $I L-8$ mRNA expression was analysed by quantitative real-time reverse transcriptase (RT)-PCR (Sunaga et al, 2012). Briefly, total RNA was extracted using the RNeasy mini kit (Qiagen, Valencia, CA, USA), and cDNA was synthesised from $2 \mu \mathrm{g}$ of total RNA with the SuperScript II FirstStrand Synthesis system using the oligo(dT) primer (Invitrogen, Carlsbad, CA, USA). Primers and probes for $I L-8$ and GAPDH were purchased from Applied Biosystems (Tokyo, Japan; assay ID: Hs00174103_m1 for IL-8 and Hs99999905_m1 for GAPDH). Realtime PCR was performed using a Lightcycler 480 system (Roche Diagnostics, Tokyo, Japan). Quantitative analysis was performed using the GAPDH gene as an internal reference to normalise the input cDNA. The comparative $\mathrm{Ct}$ method was used to compute relative expression values. As for $I L-8 \mathrm{mRNA}$ expression analysis, we had validated that $I L-8$ mRNA levels were strongly correlated with IL-8 protein levels in the cultured medium in NSCLC cell lines (Supplementary Figure $1 ; r=0.818, P<0.001$ ) as evaluated by enzyme-linked immunosorbent assay (Sunaga et al, 2012).

Immunohistochemical staining. Immunohistochemical staining for IL-8 and CD34 was performed according to the procedure as previously described (Kaira et al, 2012). A rabbit polyclonal antibody against IL-8 (Abcam, Cambridge, MA, USA) and a mouse monoclonal antibody against CD34 (Nichirei, Tokyo, Japan) were used. The intensity of IL-8 staining was scored as follows: $1,<10 \%$ of tumour area stained; 2, 10-25\% stained; 3, 26-50\% stained; and $4,>50 \%$ stained. The tumours that had a score of more than 3 were defined as having high expression. The number of CD34-positive vessels was counted in four selected hot spots in a $\times 400$ field $\left(0.26-\mathrm{mm}^{2}\right.$ field area). The mean value of two independent readings of the same specimen was calculated.

Figure 1. IL-8 mRNA expression in 136 surgical specimens from lung adenocarcinoma patients. (A) Comparisons of IL-8 expression between patients who were $\geqslant 70$ years old and those who were $<70$ years old; between males and females; between smokers and non-smokers; and between patients with different pathological tumour stages. (B) Comparisons of IL-8 expression between patients who were $\geqslant 70$ years old and those who were $<70$ years old in the smoker subgroup and the non-smoker subgroup. (C) Correlations between IL- 8 expression and age in smokers and non-smokers. (D) Comparisons of IL-8 expression between tumours with or without pleural involvement; tumours with or without lymphatic permeation; and tumours with or without vascular invasion. (E) Differential IL-8 expression among the three groups that were classified according to KRAS and EGFR mutation status. (F) Comparisons of IL-8 expression between $\geqslant 70$-year-old patients and $<70$-year-old patients in the KRAS-mutants, EGFR-mutants and wild-type EGFR/KRAS subgroups. (G) Correlations between IL-8 expression and age in the KRAS-mutant, EGFR-mutant and wild-type EGFR/KRAS subgroups. (H) Significant correlations between IL-8 expression and age in non-smokers with KRAS mutations and non-smokers with EGFR mutations. (I) Comparisons of IL-8 expression between smokers and non-smokers in the KRAS-mutant, EGFR-mutant and wild-type EGFR/KRAS subgroups. IL-8 expression levels were determined by quantitative RT-PCR analysis and normalised to the mean values (=1 a.u.) from 10 non-cancerous lung tissue samples. The points represent the mean $I L-8$ levels obtained from four independent experiments. Differences between two groups were tested with the Mann-Whitney test, and differences between three or more groups were tested with the Kruskal-Wallis test. 
Statistical analysis. The data were statistically analysed with GraphPad Prism 5 for Mac OS X (GraphPad Software, San Diego, CA, USA). Differences between two groups were analysed by Mann-Whitney test and differences between more than two groups were analysed by Kruskal-Wallis test. The correlation between different variables was analysed using the non-parametric Spearman's rank test. The Kaplan-Meier method was used to estimate survival as a function of time, and survival differences
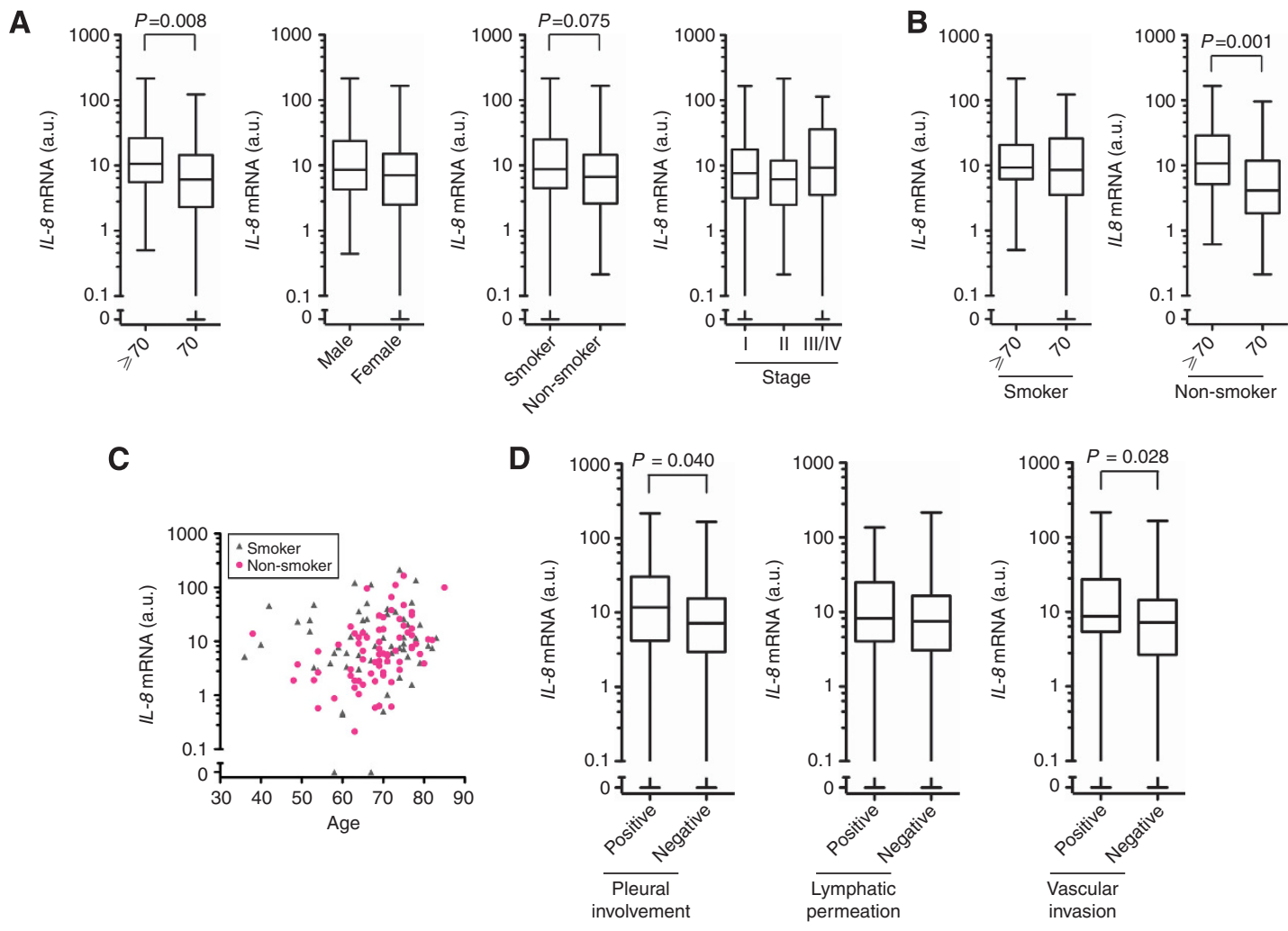

E

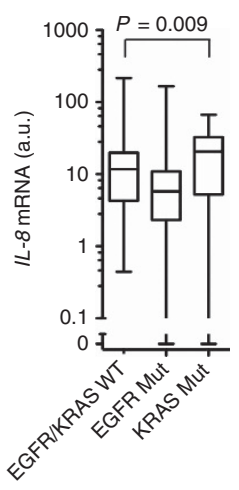

$\mathbf{F}$

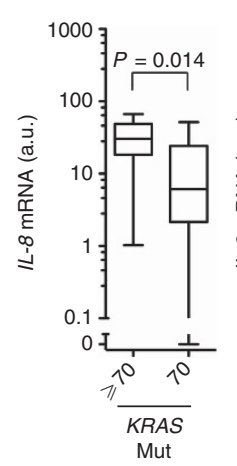

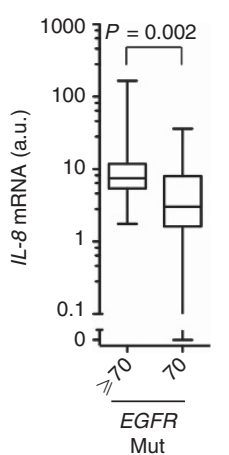

I

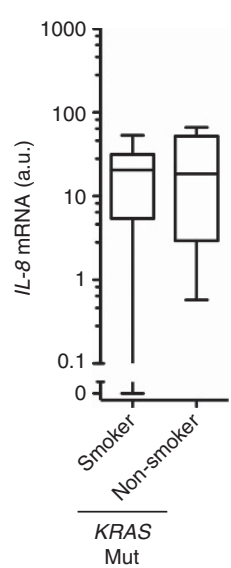

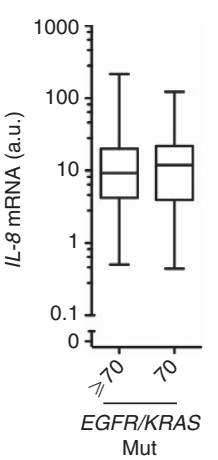

G
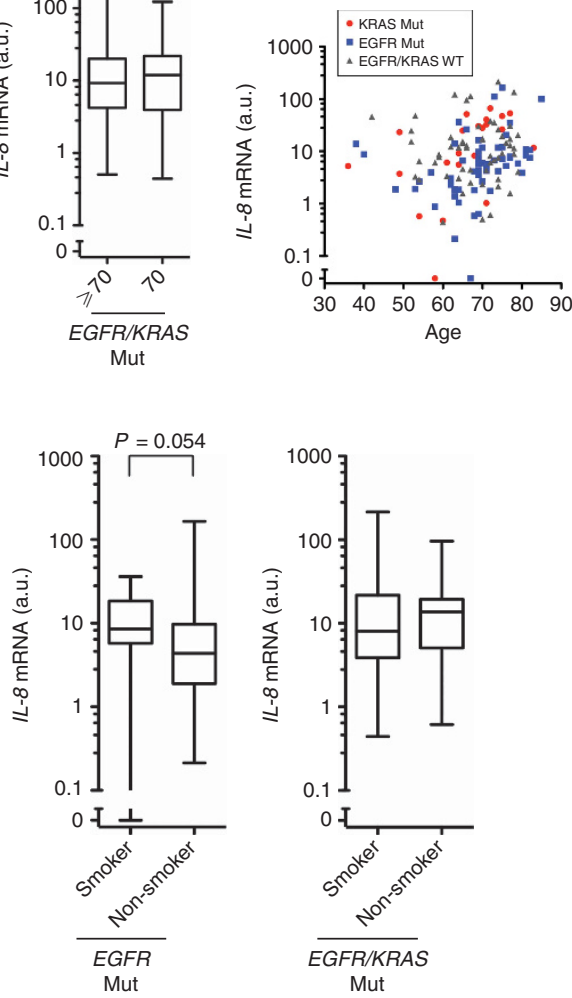

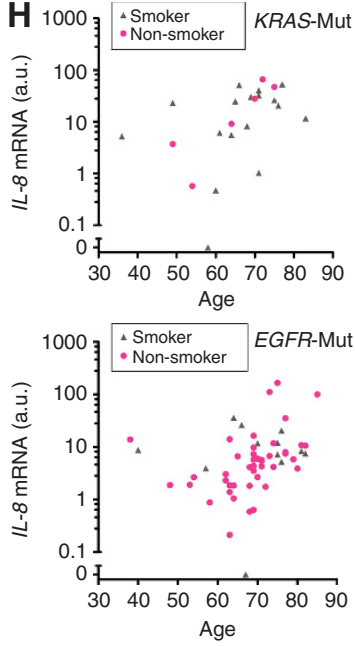


were analysed by the log-rank test. Multivariate analyses were performed with StatView version 5.0 software (SAS Institute Inc., Cary, NC, USA) using a stepwise Cox proportional hazards model to identify independent prognostic factors. $P<0.05$ was considered significant and $0.1>P \geqslant 0.05$ was considered borderline significant.

\section{RESULTS}

IL-8 mRNA expression was examined in 136 surgical specimens from primary lung adenocarcinoma patients, and the association between $I L-8$ expression and clinicopathological parameters was analysed. $I L-8$ expression was significantly higher in tumours from patients who were $\geqslant 70$ years old than in those from patients who were $<70$ years old $(P=0.008)$ and was higher in tumours from smokers than in those from non-smokers with borderline significance $(P=0.075)$, whereas there were no significant differences in IL-8 expression on the basis of gender or pathological stage (Figure 1A). When the patient population was classified into four groups according to age and smoking history, a significant difference in $I L-8$ expression levels was observed only in the non-smoker subgroup (Figure $1 \mathrm{~B} ; P=0.001$ ). There was a significant correlation between age and $I L-8$ expression among the non-smokers but not among the smokers (Figure 1C; $r=0.436, P<0.001$ ), indicating that $I L-8$ expression levels might increase with age when patients have no history of smoking. In regard to pathological factors, $I L-8$ expression was significantly higher in tumours with pleural involvement (PI; $P=0.040)$ or vascular invasion (VI; $P=0.028)$ than in those without such characteristics (Figure 1D). We also validated that IL- 8 protein was highly expressed in tumour cells of lung adenocarcinoma specimens with high $I L-8$ mRNA levels (Supplementary Figure 2) and that $I L-8$ mRNA expression was significantly correlated with IL-8 protein score $(r=0.526, P<0.001)$, indicating that the results obtained from the $I L-8$ mRNA expression analysis are also valid at the protein level.

We next examined the association between $I L-8$ expression and the mutation status of KRAS and EGFR. IL- 8 was differentially expressed among groups in which the mutation status of KRAS and $E G F R$ differed (Figure 1E; $P=0.009$ ); $I L-8$ was more highly expressed in tumours with KRAS mutations than in those with wild-type KRAS/EGFR or with EGFR mutations. We further examined whether $I L-8$ expression levels differed according to age or smoking history in these three subgroups. In both KRAS-mutant and EGFR-mutant subgroups, $I L-8$ expression was significantly higher in tumours from patients who were $\geqslant 70$ years old (Figure 1F; KRAS-mutants: $P=0.014$; EGFR-mutants: $P=0.002$ ). There was a significant correlation between age and $I L-8$ expression (Figure 1G; KRAS-mutants: $r=0.628, \quad P=0.001$; EGFR-mutants: $r=0.452, P<0.001)$. When these subgroups were further classified by smoking history, the significant correlation between age and $I L-8$ expression was limited to the non-smoker subgroups (Figure $1 \mathrm{H}$; KRAS-mutants: $r=0.886, P=0.033$; EGFRmutants: $r=0.549, P<0.001)$. In addition, $I L-8$ expression was higher in the tumours of smokers than in those of non-smokers with borderline significance only in the EGFR-mutant subgroup (Figure 1I; $P=0.054$ ).

As IL- 8 has been well described as an angiogenic factor, we evaluated expression of CD34, an angiogenic marker, in the tumour specimens from lung adenocarcinoma patients. There is a significant correlation between CD34 scores and $I L-8$ mRNA levels (Figure 2A; $r=0.221, P=0.011)$. When the tumour specimens were classified according to EGFR and KRAS mutation status, the correlation between CD34 and $I L-8$ expression appears to be stronger in KRAS-mutated tumours $(r=0.352, P=0.108)$ compared with those with EGFR-mutant $(r=0.096, P=0.495)$ or those with wild-type $E G F R / K R A S$ ( $r=0.133, P=0.329$ ), although there were no significant correlations in each group. Furthermore, when
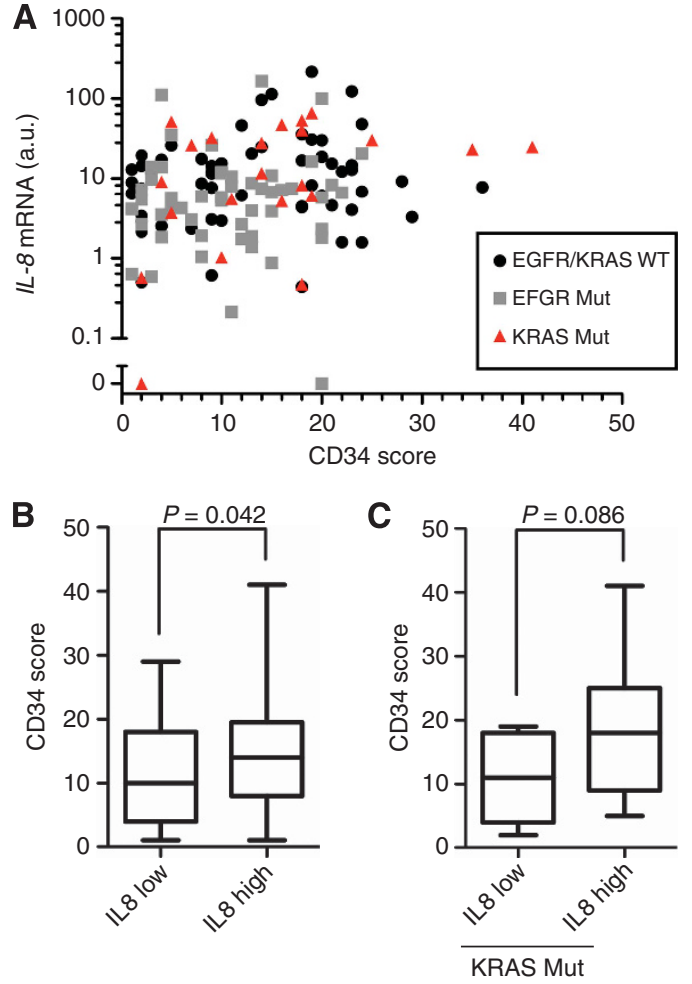

Figure 2. (A) Correlations between IL-8 expression and CD34 score in lung adenocarcinomas. Grey squares: EGFR-mutants; red triangles: KRAS-mutants; black circles: tumours with wild-type EGFR/KRAS. Comparisons of CD34 score between lung adenocarcinomas with high IL-8 expression and those with low IL-8 expression (cut-off point: the median IL-8 level) in (B) the whole group or (C) the KRAS-mutants subgroup.

the tumours were divided into two groups according to $I L-8$ mRNA expression levels, CD34 levels were significantly higher in tumours with high $I L-8$ than in those with low $I L-8$ (Figure 2B; $P=0.042)$. In the KRAS-mutated tumours, CD34 levels tended to be higher in tumours with high $I L-8$ levels than in those with low $I L-8$ levels (Figure $2 \mathrm{C} ; P=0.086$ ). These findings suggest that IL-8 could have an important role in tumour progression by participating tumour angiogenesis, especially in KRAS-mutated lung adenocarcinomas.

We next assessed the prognostic significance of $I L-8$ expression in 119 patients with lung adenocarcinomas who had not received EGFR-TKI therapy. The patients with high $I L-8$ expression had significantly shorter DFS (Figure 3A; $P=0.006$ ) and $\mathrm{OS}$ (Figure $3 \mathrm{~B} ; P=0.005$ ) compared with those with low $I L-8$ expression. Considering that oncogenic KRAS-induced IL-8 overexpression contributes to aggressive phenotypes of NSCLC (Sunaga et al, 2012), we hypothesised that KRAS mutation would negatively affect the survival of lung adenocarcinoma patients who also have high $I L-8$ expression. When the patient population was classified into four groups according to IL-8 expression level and KRAS mutation status, the patients with $I L-8$-high and KRAS-mutant tumours had significantly shorter DFS (Figure 3C; $P=0.001$ ) and OS (Figure 3D; $P=0.007$ ) than those with $I L-8$-low and KRAS wild-type tumours. Furthermore, univariate Cox regression analysis revealed that smoking history, advanced pathological stage, presence of PI, lymphatic permeation (LP) or VI, presence of KRAS mutation, absence of EGFR mutation and elevated $I L-8$ expression were all unfavourable prognostic factors for DFS (Table 1). Similarly, smoking history, advanced pathological stage, presence of PI, LP or VI, presence of KRAS mutation and elevated $I L-8$ expression were unfavourable prognostic factors for OS 

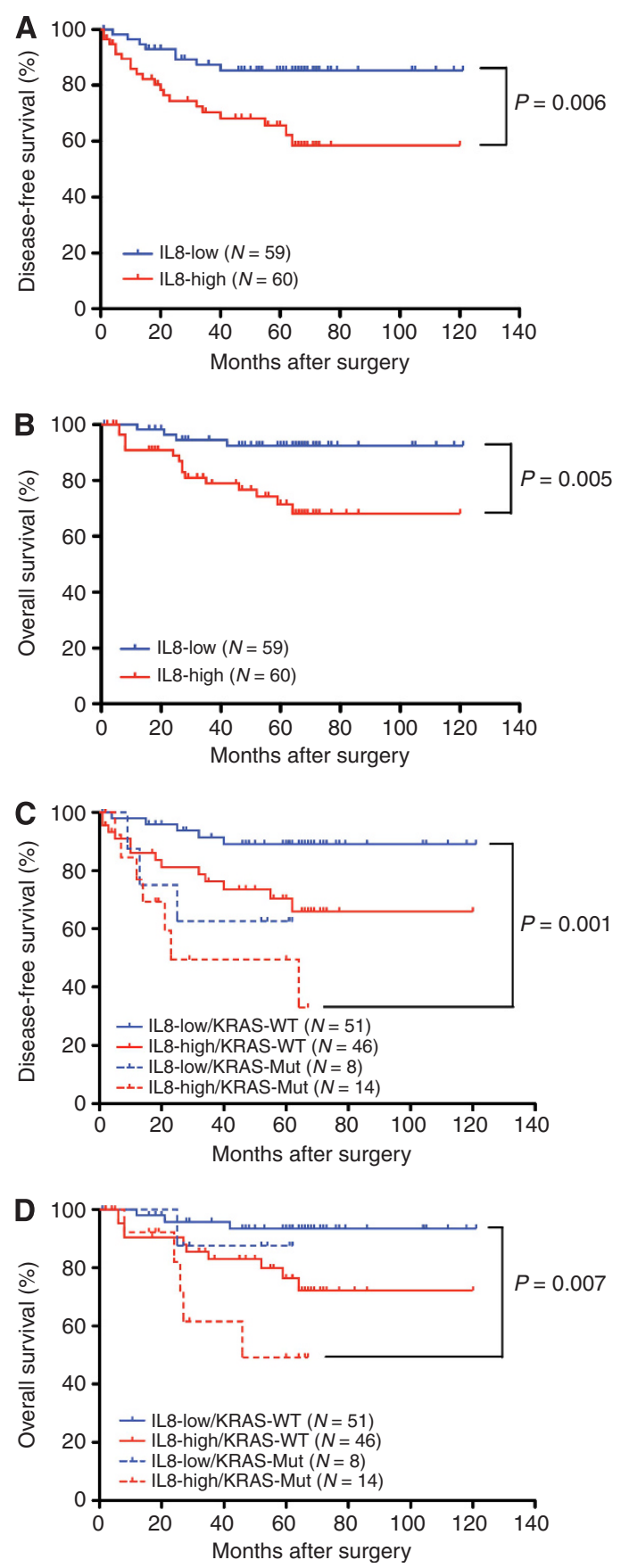

Figure 3. Kaplan-Meier analysis of (A) disease-free survival (DFS) and (B) overall survival (OS) in 119 lung adenocarcinoma patients who had not received EGFR-TKI therapy. The patients were classified into two groups with low IL-8 expression and those with high IL-8 expression according to the median IL-8 level. Differences in DFS and OS were analysed with the log-rank test. Comparison of (C) DFS and (D) OS in four subgroups according to IL-8 expression levels and KRAS mutation status. KRAS-WT, KRAS wild-type; KRAS-Mut, KRAS-mutant.

Differences in DFS and OS between IL-8-High/KRAS-Mut and IL-8-Low/ KRAS-WT were analysed with the log-rank test with Bonferroni's correction for multiple comparisons.

(Table 1). Multivariate analysis showed that elevated $I L-8$ expression remained an unfavourable prognostic factor for both DFS and OS even after adjustment for pathological stage (Table 1). These results indicate that elevated $I L-8$ expression is a biomarker for unfavourable prognosis in lung adenocarcinoma patients, especially in those with KRAS mutations.
DISCUSSION

We recently reported the association between $I L-8$ expression, KRAS mutations and certain clinicopathological parameters of NSCLC and the potential role of IL- 8 as a therapeutic target (Sunaga et al, 2012). Here, we extended our recent study to include 136 primary lung adenocarcinomas, to further elucidate the clinicopathological and prognostic significance of $I L-8$ expression in lung adenocarcinomas. We found that $I L-8$ expression was higher in lung adenocarcinomas from elderly patients and smokers. A recent study demonstrated that an increased level of circulating IL-8 is associated with a lung cancer risk several years before diagnosis (Pine et al, 2011), suggesting that IL-8 has a critical role in lung tumour initiation. In fact, IL- 8 was shown to be upregulated in smokers with lung cancer in a microarray study comparing gene expression in normal large-airway epithelial cells between smokers with or without lung cancer (Spira et al, 2007). Other studies have implicated tobacco smoking as one of the possible mechanisms for IL-8 upregulation in bronchial epithelial cells (Kuschner et al, 1996; Mio et al, 1997; Chalmers et al, 2001). It is thus likely that IL-8 upregulation in bronchial epithelial cells induced by tobacco smoking is involved in the carcinogenesis of lung adenocarcinomas. On the other hand, IL-8 expression positively correlated with age in our non-smoker subgroup. Cellular senescence is part of the aging process (Collado et al, 2007; Lopez-Otin et al, 2013), and is accompanied by a senescenceassociated secretory phenotype (SASP) that involves a marked increase in the secretion of proinflammatory cytokines (Coppe et al, 2008). SASP is thought to have a role in tumour progression (Davalos et al, 2010), and one of the most upregulated cytokines in SASP is IL-8, which is expressed in premalignant epithelial cells (Kuilman et al, 2008; Davalos et al, 2010). Therefore, age-related IL-8 upregulation in bronchial epithelial cells may be one of the mechanisms that lead to the development of lung adenocarcinomas in non-smokers. Further investigation regarding the $I L-8$ levels in normal lung tissues stratified by age are needed to address this issue.

In the present study, $I L-8$ was preferentially expressed in lung adenocarcinomas with pleural involvement and vascular invasion, which contribute to aggressive tumour phenotypes. Furthermore, elevated IL-8 expression was associated with unfavourable prognosis in lung adenocarcinoma patients. Our results are consistent with those of previous studies that showed a correlation between high $I L-8$ mRNA expression or IL-8 protein expression and poor prognosis in NSCLC patients (Bellocq et al, 1998; Yuan et al, 2000; Chen et al, 2003; Seike et al, 2007), although the number of lung adenocarcinoma patients was relatively small in these studies. In addition, we found that the presence of KRAS mutation along with high IL-8 expression in tumours was associated with the worst prognosis for patients with lung adenocarcinoma. Given that KRAS mutation induces IL-8 overexpression in lung adenocarcinoma cells (Sunaga et al, 2012), elevated IL-8 expression is likely to be a biomarker for predicting unfavourable clinical outcome in patients with lung adenocarcinoma who have KRAS mutations.

Many human cancers, including lung adenocarcinomas, overexpress IL-8 (Xie, 2001; Sunaga et al, 2012). Secreted IL-8 from tumour cells activates downstream signalling pathways that regulate many cellular processes including cell proliferation, migration, invasion and angiogenesis to promote tumour progression and metastasis (Waugh and Wilson, 2008). In particular, IL-8 is a well-known angiogenic factor and intratumoural IL-8 expression has been shown to be associated with angiogenesis in NSCLC (Yuan et al, 2000; Masuya et al, 2001; Boldrini et al, 2005). Anti-angiogenesis therapy is a key strategy for treating NSCLC. Several anti-angiogenic agents including bevacizumab are currently 
Table 1. Cox regression analysis for survival in 119 patients with lung adenocarcinomas

\begin{tabular}{|c|c|c|c|}
\hline Variable & Hazard ratio & $95 \%$ Confidence interval & $P$-value \\
\hline \multicolumn{4}{|l|}{ Disease-free survival } \\
\hline \multicolumn{4}{|l|}{ Univariate analysis } \\
\hline $\begin{array}{l}\text { Age ( } \geqslant 70 \text { vs <70) } \\
\text { Gender (male vs female) } \\
\text { Smoking history (smoker vs non-smoker) } \\
\text { Stage (III-IV vs I-II) } \\
\text { Pleural involvement (positive vs negative) } \\
\text { Lymphatic permeation (positive vs negative) } \\
\text { Vascular invasion (positive vs negative) } \\
\text { KRAS gene (mutation vs wild-type) } \\
\text { EGFR gene (mutation vs wild-type) } \\
\text { IL8 expression (as continuous variable) }\end{array}$ & $\begin{array}{l}1.194 \\
1.644 \\
2.650 \\
9.048 \\
7.116 \\
3.912 \\
9.514 \\
3.093 \\
0.381 \\
1.011\end{array}$ & $\begin{array}{c}0.576-2.476 \\
0.787-3.434 \\
1.227-5.723 \\
4.305-19.018 \\
3.135-16.154 \\
1.771-8.639 \\
3.596-25.170 \\
1.426-6.709 \\
0.155-0.939 \\
1.006-1.017\end{array}$ & $\begin{array}{r}0.634 \\
0.186 \\
0.013 \\
<0.001 \\
<0.001 \\
<0.001 \\
<0.001 \\
0.004 \\
0.036 \\
<0.001\end{array}$ \\
\hline \multicolumn{4}{|l|}{ Multivariate analysis } \\
\hline $\begin{array}{l}\text { Stage (III-IV vs I-II) } \\
\text { IL-8 expression (as continuous variable) }\end{array}$ & $\begin{array}{l}9.594 \\
1.013\end{array}$ & $\begin{array}{c}4.484-20.530 \\
1.007-1.020\end{array}$ & $\begin{array}{l}<0.001 \\
<0.001\end{array}$ \\
\hline \multicolumn{4}{|l|}{ Overall survival } \\
\hline \multicolumn{4}{|l|}{ Univariate analysis } \\
\hline $\begin{array}{l}\text { Age ( } \geqslant 70 \text { vs <70) } \\
\text { Gender (male vs female) } \\
\text { Smoking history (smoker vs non-smoker) } \\
\text { Stage (III-IV vs I-II) } \\
\text { Pleural involvement (positive vs negative) } \\
\text { Lymphatic permeation (positive vs negative) } \\
\text { Vascular invasion (positive vs negative) } \\
\text { KRAS gene (mutation vs wild-type) } \\
\text { EGFR gene (mutation vs wild-type) } \\
\text { IL-8 expression (as continuous variable) }\end{array}$ & $\begin{array}{r}1.428 \\
2.063 \\
2.622 \\
10.637 \\
9.613 \\
6.973 \\
10.116 \\
2.480 \\
0.371 \\
1.012 \\
\end{array}$ & $\begin{array}{c}0.591-3.450 \\
0.839-5.075 \\
1.041-6.601 \\
4.313-26.230 \\
3.205-28.839 \\
2.319-20.967 \\
2.946-34.735 \\
0.944-6.516 \\
0.124-1.113 \\
1.006-1.018\end{array}$ & $\begin{array}{r}0.428 \\
0.115 \\
0.041 \\
<0.001 \\
<0.001 \\
<0.001 \\
<0.001 \\
0.065 \\
0.077 \\
<0.001\end{array}$ \\
\hline \multicolumn{4}{|l|}{ Multivariate analysis } \\
\hline $\begin{array}{l}\text { Stage (III-IV vs I-II) } \\
\text { IL-8 expression (as continuous variable) }\end{array}$ & $\begin{array}{r}10.700 \\
1.014\end{array}$ & $\begin{array}{c}4.254-26.913 \\
1.007-1.022\end{array}$ & $\begin{array}{l}<0.001 \\
<0.001\end{array}$ \\
\hline
\end{tabular}

used or being tested for the treatment of NSCLC patients (Horn and Sandler, 2009). In addition, several researchers including our group have demonstrated that attenuation of IL-8 leads to inhibition of cell proliferation, migration and angiogenesis in NSCLC (Smith et al, 1994; Arenberg et al, 1996; Yatsunami et al, 1997; Zhu et al, 2004; Sunaga et al, 2012). Importantly, IL-8 was shown to be upregulated in human cancers including NSCLC harbouring the oncogenic KRAS mutation (Sparmann and BarSagi, 2004; Wislez et al, 2006; Sunaga et al, 2012), which is one of the most common driver mutations in lung adenocarcinoma (Pao and Hutchinson, 2012). Thus, targeting IL-8 may be an attractive therapeutic option to improve the survival of patients with oncogenic KRAS-driven lung adenocarcinoma.

In conclusion, the present study suggests that IL- 8 expression is a predictor of unfavourable prognosis for lung adenocarcinoma patients, especially for those with KRAS mutation. Although tobacco smoking is likely to be one mechanism that is linked to IL-8 upregulation, aging may be the main cause of IL-8 overexpression in lung adenocarcinomas arising in non-smokers. Our findings also raise the possibility that an anti-IL- 8 therapeutic strategy could improve the clinical outcome in patients with oncogenic KRAS-driven lung adenocarcinoma.

\section{ACKNOWLEDGEMENTS}

We thank Dr Keita Mori of the Clinical Trial Coordination Office, Shizuoka Cancer Center, Shizuoka, Japan for the critical advice on statistical analysis. This work was funded by Grant 18790532 (to NS) from the Ministry of Education, Culture, Sports, Science and Technology, Japan.

\section{CONFLICT OF INTEREST}

The authors declare no conflict of interest.

\section{REFERENCES}

Arenberg DA, Kunkel SL, Polverini PJ, Glass M, Burdick MD, Strieter RM (1996) Inhibition of interleukin-8 reduces tumorigenesis of human non-small cell lung cancer in SCID mice. J Clin Invest 97: 2792-2802.

Bellocq A, Antoine M, Flahault A, Philippe C, Crestani B, Bernaudin JF, Mayaud C, Milleron B, Baud L, Cadranel J (1998) Neutrophil alveolitis in bronchioloalveolar carcinoma: induction by tumor-derived interleukin-8 and relation to clinical outcome. Am J Pathol 152: 83-92.

Boldrini L, Gisfredi S, Ursino S, Lucchi M, Mussi A, Basolo F, Pingitore R, Fontanini G (2005) Interleukin-8 in non-small cell lung carcinoma: relation with angiogenic pattern and p53 alterations. Lung Cancer 50: 309-317.

Chalmers GW, MacLeod KJ, Thomson L, Little SA, McSharry C, Thomson NC (2001) Smoking and airway inflammation in patients with mild asthma. Chest 120: 1917-1922.

Chen JJ, Yao PL, Yuan A, Hong TM, Shun CT, Kuo ML, Lee YC, Yang PC (2003) Up-regulation of tumor interleukin-8 expression by infiltrating macrophages: its correlation with tumor angiogenesis and patient survival in non-small cell lung cancer. Clin Cancer Res 9: 729-737.

Chin LP, Soo RA, Soong R, Ou SH (2012) Targeting ROS1 with anaplastic lymphoma kinase inhibitors: a promising therapeutic strategy for a newly 
defined molecular subset of non-small-cell lung cancer. J Thorac Oncol 7: $1625-1630$.

Collado M, Blasco MA, Serrano M (2007) Cellular senescence in cancer and aging. Cell 130: 223-233.

Coppe JP, Patil CK, Rodier F, Sun Y, Munoz DP, Goldstein J, Nelson PS, Desprez PY, Campisi J (2008) Senescence-associated secretory phenotypes reveal cell-nonautonomous functions of oncogenic RAS and the p53 tumor suppressor. PLoS Biology 6: 2853-2868.

Davalos AR, Coppe JP, Campisi J, Desprez PY (2010) Senescent cells as a source of inflammatory factors for tumor progression. Cancer Metastasis Rev 29: $273-283$.

Horn L, Sandler AB (2009) Angiogenesis in the treatment of non-small cell lung cancer. Proc Am Thorac Soc 6: 206-217.

Jemal A, Bray F, Center MM, Ferlay J, Ward E, Forman D (2011) Global cancer statistics. CA Cancer J Clin 61: 69-90.

Kaira K, Sunose Y, Arakawa K, Ogawa T, Sunaga N, Shimizu K, Tominaga H, Oriuchi N, Itoh H, Nagamori S, Kanai Y, Segawa A, Furuya M, Mori M, Oyama T, Takeyoshi I (2012) Prognostic significance of L-type amino-acid transporter 1 expression in surgically resected pancreatic cancer. $\mathrm{Br} \mathrm{J}$ Cancer 107: 632-638.

Kuilman T, Michaloglou C, Vredeveld LC, Douma S, van Doorn R, Desmet CJ, Aarden LA, Mooi WJ, Peeper DS (2008) Oncogene-induced senescence relayed by an interleukin-dependent inflammatory network. Cell 133: 1019-1031.

Kuschner WG, D’Alessandro A, Wong H, Blanc PD (1996) Dose-dependent cigarette smoking-related inflammatory responses in healthy adults. Eur Respir J 9: 1989-1994.

Lopez-Otin C, Blasco MA, Partridge L, Serrano M, Kroemer G (2013) The hallmarks of aging. Cell 153: 1194-1217.

Luppi F, Longo AM, de Boer WI, Rabe KF, Hiemstra PS (2007) Interleukin-8 stimulates cell proliferation in non-small cell lung cancer through epidermal growth factor receptor transactivation. Lung Cancer 56: 25-33.

Mascaux C, Iannino N, Martin B, Paesmans M, Berghmans T, Dusart M, Haller A, Lothaire P, Meert AP, Noel S, Lafitte JJ, Sculier JP (2005) The role of RAS oncogene in survival of patients with lung cancer: a systematic review of the literature with meta-analysis. Br J Cancer 92: 131-139.

Masuya D, Huang C, Liu D, Kameyama K, Hayashi E, Yamauchi A, Kobayashi S, Haba R, Yokomise H (2001) The intratumoral expression of vascular endothelial growth factor and interleukin-8 associated with angiogenesis in nonsmall cell lung carcinoma patients. Cancer 92: 2628-2638.

Mio T, Romberger DJ, Thompson AB, Robbins RA, Heires A, Rennard SI (1997) Cigarette smoke induces interleukin-8 release from human bronchial epithelial cells. Am J Respir Crit Care Med 155: 1770-1776.

Mitani Y, Lezhava A, Kawai Y, Kikuchi T, Oguchi-Katayama A, Kogo Y, Itoh M, Miyagi T, Takakura H, Hoshi K, Kato C, Arakawa T, Shibata K, Fukui K, Masui R, Kuramitsu S, Kiyotani K, Chalk A, Tsunekawa K, Murakami M, Kamataki T, Oka T, Shimada H, Cizdziel PE, Hayashizaki Y (2007) Rapid SNP diagnostics using asymmetric isothermal amplification and a new mismatch-suppression technology. Nat Methods 4: 257-262.

Miyamae Y, Shimizu K, Mitani Y, Araki T, Kawai Y, Baba M, Kakegawa S, Sugano M, Kaira K, Lezhava A, Hayashizaki Y, Yamamoto K, Takeyoshi I (2010) Mutation detection of epidermal growth factor receptor and KRAS genes using the smart amplification process version 2 from formalin-fixed, paraffin-embedded lung cancer tissue. J Mol Diagn 12: 257-264.

Palena C, Hamilton DH, Fernando RI (2012) Influence of IL-8 on the epithelial-mesenchymal transition and the tumor microenvironment. Future Oncol 8: 713-722.

Pao W, Hutchinson KE (2012) Chipping away at the lung cancer genome. Nat Med 18: 349-351.

Pine SR, Mechanic LE, Enewold L, Chaturvedi AK, Katki HA, Zheng YL, Bowman ED, Engels EA, Caporaso NE, Harris CC (2011) Increased levels of circulating interleukin 6, interleukin 8, C-reactive protein, and risk of lung cancer. J Natl Cancer Inst 103: 1112-1122.

Seike M, Yanaihara N, Bowman ED, Zanetti KA, Budhu A, Kumamoto K, Mechanic LE, Matsumoto S, Yokota J, Shibata T, Sugimura H, Gemma A, Kudoh S, Wang XW, Harris CC (2007) Use of a cytokine gene expression signature in lung adenocarcinoma and the surrounding tissue as a prognostic classifier. J Natl Cancer Inst 99: 1257-1269.

Smith DR, Polverini PJ, Kunkel SL, Orringer MB, Whyte RI, Burdick MD, Wilke CA, Strieter RM (1994) Inhibition of interleukin 8 attenuates angiogenesis in bronchogenic carcinoma. J Exp Med 179: 1409-1415.

Sparmann A, Bar-Sagi D (2004) Ras-induced interleukin-8 expression plays a critical role in tumor growth and angiogenesis. Cancer Cell 6: 447-458.

Spira A, Beane JE, Shah V, Steiling K, Liu G, Schembri F, Gilman S, Dumas YM, Calner P, Sebastiani P, Sridhar S, Beamis J, Lamb C, Anderson T, Gerry N, Keane J, Lenburg ME, Brody JS (2007) Airway epithelial gene expression in the diagnostic evaluation of smokers with suspect lung cancer. Nat Med 13: 361-366.

Suda K, Tomizawa K, Mitsudomi T (2010) Biological and clinical significance of KRAS mutations in lung cancer: an oncogenic driver that contrasts with EGFR mutation. Cancer Metastasis Rev 29: 49-60.

Sunaga N, Imai H, Shimizu K, Shames DS, Kakegawa S, Girard L, Sato M, Kaira K, Ishizuka T, Gazdar AF, Minna JD, Mori M (2012) Oncogenic KRAS-induced interleukin-8 overexpression promotes cell growth and migration and contributes to aggressive phenotypes of non-small cell lung cancer. Int J Cancer 130: 1733-1744.

Sunaga N, Kaira K, Imai H, Shimizu K, Nakano T, Shames DS, Girard L, Soh J, Sato M, Iwasaki Y, Ishizuka T, Gazdar AF, Minna JD, Mori M (2013) Oncogenic KRAS-induced epiregulin overexpression contributes to aggressive phenotype and is a promising therapeutic target in non-small-cell lung cancer. Oncogene 32: 4034-4042.

Travis WD, Brambilla E, Noguchi M, Nicholson AG, Geisinger KR, Yatabe Y, Beer DG, Powell CA, Riely GJ, Van Schil PE, Garg K, Austin JH, Asamura H, Rusch VW, Hirsch FR, Scagliotti G, Mitsudomi T, Huber RM, Ishikawa Y, Jett J, Sanchez-Cespedes M, Sculier JP, Takahashi T, Tsuboi M, Vansteenkiste J, Wistuba I, Yang PC, Aberle D, Brambilla C, Flieder D, Franklin W, Gazdar A, Gould M, Hasleton P, Henderson D, Johnson B, Johnson D, Kerr K, Kuriyama K, Lee JS, Miller VA, Petersen I, Roggli V, Rosell R, Saijo N, Thunnissen E, Tsao M, Yankelewitz D (2011) International association for the study of lung cancer/american thoracic society/european respiratory society international multidisciplinary classification of lung adenocarcinoma. J Thorac Oncol 6: 244-285.

Wang J, Huang M, Lee P, Komanduri K, Sharma S, Chen G, Dubinett SM (1996) Interleukin-8 inhibits non-small cell lung cancer proliferation: a possible role for regulation of tumor growth by autocrine and paracrine pathways. J Interferon Cytokine Res 16: 53-60.

Waugh DJ, Wilson C (2008) The interleukin-8 pathway in cancer. Clin Cancer Res 14: 6735-6741.

Wislez M, Fujimoto N, Izzo JG, Hanna AE, Cody DD, Langley RR, Tang H, Burdick MD, Sato M, Minna JD, Mao L, Wistuba I, Strieter RM, Kurie JM (2006) High expression of ligands for chemokine receptor CXCR2 in alveolar epithelial neoplasia induced by oncogenic kras. Cancer Res $\mathbf{6 6}$ : 4198-4207.

Xie K (2001) Interleukin-8 and human cancer biology. Cytokine Growth Factor Rev 12: 375-391.

Yatsunami J, Tsuruta N, Ogata K, Wakamatsu K, Takayama K, Kawasaki M, Nakanishi Y, Hara N, Hayashi S (1997) Interleukin-8 participates in angiogenesis in non-small cell, but not small cell carcinoma of the lung. Cancer Lett 120: 101-108.

Yuan A, Yang PC, Yu CJ, Chen WJ, Lin FY, Kuo SH, Luh KT (2000) Interleukin-8 messenger ribonucleic acid expression correlates with tumor progression, tumor angiogenesis, patient survival, and timing of relapse in non-small-cell lung cancer. Am J Respir Crit Care Med 162: 1957-1963.

Zhu YM, Webster SJ, Flower D, Woll PJ (2004) Interleukin-8/CXCL8 is a growth factor for human lung cancer cells. Br J Cancer 91: 1970-1976.

This work is published under the standard license to publish agreement. After 12 months the work will become freely available and the license terms will switch to a Creative Commons AttributionNonCommercial-Share Alike 3.0 Unported License.

Supplementary Information accompanies this paper on British Journal of Cancer website (http://www.nature.com/bjc) 